\title{
The Tensile Properties of Single Iron Crystals.
}

$A^{\mathrm{T}}$ the autumn meeting of the Iron and Steel A Institute held in Birmingham on September 9-II, Prof. C. A. Edwards and Mr. L. B. Pfeil presented a continuation of their work on the subject of the tensile properties of single iron crystals. Eighteen months ago, they succeeded in preparing some large iron crystals by the method of straining and heating introduced by Carpenter and Elam. The

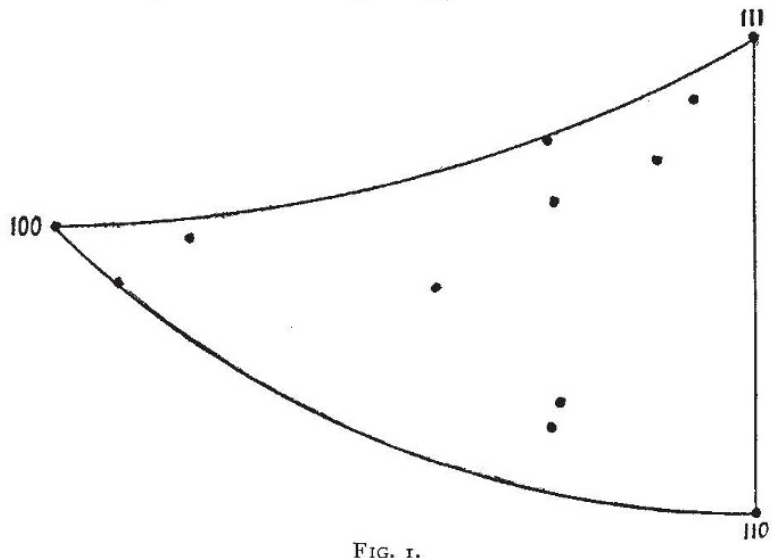

large crystals described in the present paper were prepared by this method, although some small modifications have been introduced which allow them to be made with greater certainty. This method consists, briefly, in so treating the original mild steel sheets as to obtain a grain size of I20 per square $\mathrm{mm}$. Suitable strips were decarburised at $875^{\circ}$ C. for 48 hours, heated to $1000^{\circ} \mathrm{C}$. for I 2 hours, and finally slowly cooled. In this way a number of strips 8 in. $\times \mathrm{I}^{\frac{1}{2}}$ in. $\times \frac{1}{8}$ in. were obtained, each strip consisting of one large crystal in the central part. In all cases it was necessary to remove the surface film of fine crystals by carefully filing before the existence of the large crystals could be detected by light etching. Test-pieces were cut from these with the aid of a manganese templet. This ensured that they were all of the same size and minimised the risk of bending of the metal, which is very soft. The testpieces were 2.5 in. $\times 0.75$ in. $\times 0.1$ ro in.

The stress elongation curves obtained show that up to about two tons per square inch the strain was proportional to the stress, and further that there was no well-defined yield point. In this respect, therefore, single crystals of iron behaved quite differently from the ordinary microcrystalline metal, which has a well-defined yield point and approximated much more nearly to a non-ferrous metal such as copper. Later on in the paper the authors give a diagram showing the gradual development of a yield point in this iron as the size of the crystals is diminished and crystal boundaries come more and more into play. It may, therefore, be concluded that this very characteristic property of microcrystalline iron is due in some way to the influence of the crystal boundaries. The limits of proportionality of ten crystals were determined and were found to vary from $I .72$ to 2.52 tons per square inch, with a mean figure of 2.I9. It is possible, however, that these values are too high, since the filing of the specimens will in all probability have caused some work hardening of the metal. The limit of proportionality of microcrystalline iron is about eight tons per square inch, so that the values for single crystals are little more than a quarter of this and may possibly be even less.

No. 2920 , voL. I I6]
Tensile strength determinations were carried out on 25 crystals. Eighteen of these give figures in the neighbourhood of Io tons per square inch. The corresponding figure for microcrystalline iron is about 20 tons, so that the tenacity of the single crystal in more than two-thirds of the test-pieces is only about half that of the metal in the ordinary form. In the remaining 7 single crystal test-pieces, however, the values varied from is to, in one case, I5.38. In this case, therefore, the tenacity of the single crystal was fully three-quarters that of the microcrystalline metal. This figure, however, is well below the highest figure for single crystals of aluminium obtained by Carpenter and Elam, namely, 90 per cent. of the tenacity of the microcrystalline metal. It is interesting to notice that, on the whole, the single crystals possessing the highest tenacity were also the most ductile. Figures varying from 30 to 53 per cent. were obtained. Corresponding to these differences of tenacity and ductility, the crystals distorted in different ways during the tests. The majority of test-pieces broke similarly to type II. of the aluminium crystals described by Carpenter and Flam; that is, the crystals retained their width but diminished in thickness. At the fracture they drew down to a knife edge and parted in a straight line nearly at right angles to the axis of the test-piece. Crystals which gave a higher tenacity and ductility both narrowed and thinned and showed a marked tendency for the cross section to change from a rectangle to a parallelogram (Carpenter and Elam, type IV.). At the point of fracture they necked and broke without drawing to a knife edge. Just before parting a large slip occurred on a plane making an angle of $45^{\circ}$ with the length of the strip and with a "dip " of $45^{\circ}$. The crystal which broke at $\mathrm{r}_{5} .3^{8}$ tons per square inch gave a fracture different from the two types mentioned. It narrowed, thinned, and also necked.

Prof. Edwards and Mr. Pfeil have not as yet been able to determine the orientation of these crystals.

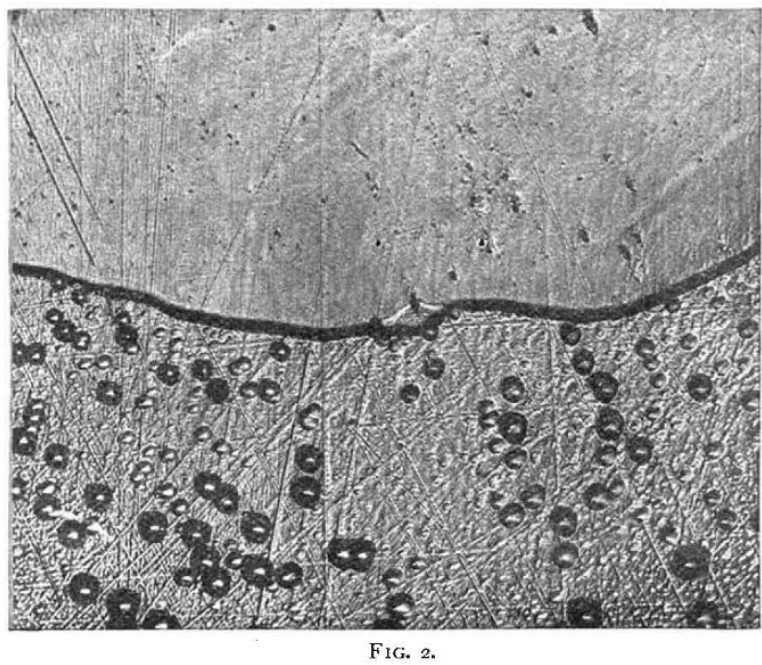

It is tolerably certain that the differences in tenacity, ductility, and method of distortion correspond to differences of original orientation of the crystals and of the method of distortion. The authors state definitely that the orientations of twelve crystals examined by them were not identical, basing this opinion on an examination under oblique illumination, and they speculate as to how it is that equal tensile strength values can be associated with variations in 
orientation. It is important to point out, however, that they do not yet know whether an iron crystal during a tension test slips upon a dodecahedral plane or cube plane, or indeed upon either of these. This work has still to be done.

A beginning, however, has been made by Miss Elam, who contributed a note at the same meeting entitled "The Orientation of Crystals Produced by Heating Strained Iron." In their previous paper, Prof. Edwards and Mr. Pfeil had stated that square etching pits were frequently obtained with a diagonal in the direction of straining, and concluded from this and other observations that the crystals were similarly oriented. Miss Elam has examined several of their single crystals by X-ray methods, and the crystal axes relative to the axis of the strip of ten crystals have been determined. Some of them have been done by her and the remainder by Mr. R. W. Aston at the Cavendish Laboratory, Cambridge. The accompanying diagram (Fig. I) represents part of the stereographic projection of the crystal axes with the positions of all the axes of the test-pieces, and hence the direction of straining, marked by a point. The relation of each point to the three principal crystal axes, i.e. the apices of the spherical triangle marked (IOO), (IIO), and (III), indicates the orientation of the crystal. This diagram shows that the points are scattered throughout the triangle and that the orientation of the crystals is consequently very varied.

Only two crystals showed cubic etching pits, and in both of these the surface of the strip was parallel to a cubic (IOO) plane in the crystal. These pits were quickly developed by etching in dilute nitric acid, whereas the other crystals appeared unattacked. When first formed the pits were rather indefiniteshaped pyramids, but on prolonged etching they became square. Crystals of other orientations showed pitting only on prolonged etching, and although the form varied from crystal to crystal, the pits had no regular shapes. Fig. 2 shows two crystals. The lower one is deeply pitted and has a cube face nearly in the plane of section. The upper one is not pitted and is attacked to a less extent although more uniformly. X-ray examination showed that the plane of the section was approximately a (II2) plane. Miss Elam's experiments show, therefore, that the single crystals produced by Messrs. Edwards and Pfeil have not necessarily the same orientation, and that it should be possible to pick out those in which a (roo) plane lies in or near the plane of section.

$$
\text { H. C. H. C. }
$$

\section{University and Educational Intelligence.}

ABERDEEN.-Kilgour research scholarships have been awarded to Miss E. H. M. Geddes (botany), and to Miss I. Dean and Mr. A. H. H. Fraser (zoology).

The University Court has appointed the following assistants: botany, Mr. N. J. G. Smith and Dr. R. Crookall; materia medica, Mr. T. J. C. Macdonald; pathology, Mr. J. Gray; zoology, Nita I. Rennet.

Birmingham.-At a meeting of the Council of the University on October 7, the following appointments were made: Dr. W'. C. Osman Hill to be demonstrator of anatomy; Miss H. I. Pfister to be lecturer in physiology; and Mr. J. F. D. Shrewsbury to be lecturer in bacteriology.

The foundations of the new buildings for the biological departments having been completed, work has been begun on the superstructure. The new building for the oil-mining departments is nearing completion.

CAmbridge.-Dr. A. C. Seward, master of Downing College and professor of botany, has entered on his second year of office as vice-chancellor.

The Cambridge University Commissioners are considering their draft of the new statutes; it is expected that it will be published before the term divides and that the final document will go to the Privy Council before the end of 1925 ; its provisions will not come into operation until the beginning of the academic year $1926-27$

For the moment local interest is focussed on the new restrictions of the motoring activities of persons in statu pupillari. Mr. D. Portway, of St. Catherine's College, has been nominated as special pro-proctor to deal with the enforcement of the new regulations. There are some members of the Senate who view any new restrictions as contrary to the "Spirit of Progress," but the discussions and voting last term showed quite clearly that a large majority felt that restriction of some kind was imperative and would be wholesome.

H.I.H. the Prince Regent of Japan, who visited the University and took an honorary degree in I92I, has presented the library with four cabinets containing the 666 volumes of the Gunsho Ruiju and a framed portrait of their blind author.

It is announced that there will be an election to an Isaac Newton Studentship (for research in astronomy or physical optics) early in the present term.

THE third annual report of the Imperial College of Tropical Agriculture, for the year ended December 3I, I924, has just been issued, and is a very satisfactory and interesting document. At the close of the year there were eighteen diploma students and fourteen post-graduates working at the College. As there were only six post-graduates on the register at the beginning of the year, the increase of this type of student is very satisfactory. The College is still hampered by lack of adequate funds for the completion and equipment of its new buildings and laboratories, and for the building of a hostel, which is so desirable an addition to the College for the proper accommodation of the students. As a result of the appeal for Ioo,oool. made by the late Lord Milner, $2 \mathrm{I}, 083 l$. were contributed during the past year, and this sum has been slightly augmented since the report was published. The report records the laying of the foundation stone of the new building of the College on January I4, I924, at which several members of the Governing Body were present, including Sir Arthur Shipley, the chairman. Reference is also made to the death of Mr. Claude Tinné Berthon, honorary consulting engineer to the College, who not only designed and superintended the erection of the Instructional Sugar Factory, but was also largely responsible for securing gifts of machinery and plant from the British Sugar Machinery Manufacturers and allied firms to the value of upwards of $20,000 \mathrm{l}$. towards its equipment. The year under review was also marked by the retirement of Sir Francis Watts, the first principal of the College, who had been Imperial Commissioner of Agriculture for the West Indies for twenty-four years. Sir Francis, in recognition of his services, was appointed, on his retirement, to the honorary position of Principal Emeritus of the College.' The report also records the appointment of Dr. Hugh Martin Leake, formerly principal of the Agricultural College, Cawnpore, to be principal of the College in succession to Sir Francis Watts.

$$
\text { NO. } 2920 \text {, VOL. I I } 6 \text { ] }
$$

